\title{
Morphology and Physical and Chemical Performance Control of Mesoporous Composite Materials
}

\author{
Huanling XIE*, AnQuan ZHENG, Jie LIU \\ The School of Chemistry and Chemical Engineering, Chongqing University of Technology, Chongqing, 400054, China \\ crossref http://dx.doi.org/10.5755/j01.ms.23.4.16235
}

Received 25 November 2016; accepted 13 April 2017

\begin{abstract}
In this study, we provide a strategy to control morphology as well as physical and chemical property of mesoporous composites materials (MCM). SEM, TEM, XRD and nitrogen adsorption-desorption measurements were used to characterize the morphology and physical and chemical performance of MCM. Low surfactant concentration results in fabrication microspheres with $5 \mathrm{gm}$ in average diameter and smooth surface. Long ultrasonic irradiation results displayed the same size microspheres that were made up of smaller particles. Longer ultrasonic irradiation brought about more diversified morphology. In the synthesis system, the introduction of a variety of inorganic salts leads to great changes in morphology and physical and chemical property of mesoporous composites materials. Such morphological, physical and chemical property mesoporous composites materials are promising for application in many fields.

Keywords: morphology, ultrasonic, surfactant concentration, inorganic salts, physical and chemical performance.
\end{abstract}

\section{INTRODUCTION}

It has been about three decades since discovery of periodic mesoporous composites materials (MCM) [1]. Recent developments have been reported on their versatile application in catalysis, separation, adsorption, drug delivery, nanocomposites, confinement of electronic materials, and environmental treatment $[2,3]$. These demand precise control of the morphologies and physical and chemical performance of the MCM [4,5]. Diversified morphologies and physical and chemical capability have effects on applications such as catalysis, separation, adsorption/desorption $[6,7]$. Therefore, many efforts were made to the morphology and physical and chemical capability control of the MCM. Typical representative of MCM was SBA-15. MCM with various morphologies and physical and chemical performance have been reported [8-23]. These methods are mainly changes in the overall composition of the synthesis mixture, including the nature of the surfactants, the silica source, cosurfactants, cosolvents, additives, and synthesis conditions such as field-assistance. Preparation for periodic mesoporous composites materials (MCM) is single-step or multi-step. Firstly, with inorganic ferric iron precursor, MCM was in situ synthesized by one-step method [24]. Secondly, different metal or metal oxide nanoparticles must be prepared. Then, the mesoporous silicas are integrated with the metal oxide nanoparticles to produce MCM with diversified framework [25-27]. Thirdly, Tao report to synthesize MCM with hydrophobic terminal ferrocene group as both the structure-directing agent and the metal oxide source by one-pot hydrothermal method [28, 29].

In this work, we report morphology and physical and chemical performance control by using ultrasonic irradiation, tuning amount of the surfactants and adding to

\footnotetext{
${ }^{*}$ Corresponding author. Tel.: +86-136-47638549.

E-mail address: xh12007@cqut.edu.cn (H.Xie)
}

inorganic salts. On the other hand, the effects of synthetic parameters, such as stirring, reactant ratio, ultrasonic admixture, ultrasonic duration, and adding additives were also examined. We focused on the study of reactant ratio, ultrasonic admixture, ultrasonic duration and adding inorganic salts affecting the morphology and physical and chemical performance of MCM.

\section{EXPERIMENTAL}

\subsection{Synthesis}

The preparation procedure of samples was as the following four steps: Firstly, triblock copolymer PluronicP123 and KCI were added to a mixture of water and $\mathrm{HCl}$ aqueous solution under vigorous stirring. Secondly, TEOS was added to this solution under magnetic stirring. Thirdly, after this procedure, this mixture was sealed in Teflon-lined stainless steel autoclaves and kept under static conditions at $30{ }^{\circ} \mathrm{C}$ for $24 \mathrm{~h}$, followed by at $100{ }^{\circ} \mathrm{C}$ for $24 \mathrm{~h}$. Fourthly, the solid products were collected by filtration, washed with water and dried. The as-synthesized SBA-15 samples were calcined in air at $550{ }^{\circ} \mathrm{C}$ for $6 \mathrm{~h}$. To pick and change parameters was as the following three classes: Firstly, the molar ratios of the reactants were 1TEOS: xP123: $1.48 \mathrm{KCl}: 6.6 \mathrm{HCl}: 170 \mathrm{H}_{2} \mathrm{O}$, where $\mathrm{x}$ is the P123 molar ratio shown in Table 1. Secondly, samples have been irradiated by different ultrasonic duration at the second step, instead of magnetic stirring, where ultrasonic duration and magnetic stirring is shown in Table 2. Thirdly, different inorganic salts were added to the reaction system, where the types and quantity of inorganic salts are shown in Table 2, also.

\subsection{Characterization}

Scanning electron microscopy (SEM) images were achieved by JEOL JSM-35CF using an acceleration voltage of $25 \mathrm{kV}$ to observe the overall morphology of the resulting materials. 
Table 1. Molar ratios of component and physical and chemical properties for synthesized MCM

\begin{tabular}{|c|c|c|c|c|c|c|}
\hline Spl & P123 & Mixing method & Time, $\min$ & TEOS/P123 & $\mathrm{d}_{100,} \mathrm{~nm}$ & Morphology \\
\hline $1-1$ & 0.0052 & ultrasonic & 8 & 192 & 8.81 & Morphology mixed with irregular particles and sphere \\
\hline $1-2$ & 0.0086 & ultrasonic & 8 & 116 & 9.32 & Sphere $(\mathrm{d}=5 \mu \mathrm{m})$ \\
\hline $1-3$ & 0.0121 & ultrasonic & 8 & 83 & 9.39 & Sphere $(\mathrm{d}=7 \mu \mathrm{m})$ \\
\hline $1-4$ & 0.0172 & ultrasonic & 8 & 58 & 9.68 & Gyroid \\
\hline $1-5$ & 0.0086 & stirring & 8 & 116 & 8.79 & Sphere $(\mathrm{d}=4 \mu \mathrm{m})$ \\
\hline $1-6$ & 0.0121 & stirring & 8 & 83 & 8.93 & Gyroid \\
\hline $1-7$ & 0.0172 & stirring & 8 & 58 & 9.16 & Gyroid-like \\
\hline
\end{tabular}

Table 2. Molar compositions and synthesis process parameters for MCM

\begin{tabular}{|c|c|c|c|c|c|c|c|}
\hline $\mathrm{Spl}$ & $\mathrm{Si}$ & $\mathrm{P} 123$ & $\mathrm{KCl}$ & $\mathrm{HCl}$ & $\mathrm{H}_{2} \mathrm{O}$ & $\mathrm{Si} / \mathrm{P} 123$ & $\mathrm{U}$ or $\mathrm{M}, \mathrm{min}^{\text {a }}$ \\
\hline $2-1$ & 1.00 & 0.0121 & 1.48 & 6.6 & 170 & 83 & $20(\mathrm{U})$ \\
\hline $2-2$ & 1.00 & 0.0121 & 1.48 & 6.6 & 170 & 83 & $60(\mathrm{U})$ \\
\hline $2-3$ & 1.00 & 0.0121 & 1.48 & 6.6 & 170 & 65 & $120(\mathrm{U})$ \\
\hline $2-4$ & 1.00 & 0.0155 & 1.48 & 6.6 & 170 & 65 & $120(\mathrm{U})$ \\
\hline $2-5$ & 1.00 & 0.0155 & 1.48 & 6.6 & 170 & 65 & $960(\mathrm{U})$ \\
\hline $2-6$ & 1.00 & 0.0155 & 1.48 & 6.6 & 170 & 65 & $1440(\mathrm{M})$ \\
\hline $2-7$ & 1.00 & 0.0155 & $0.025^{\mathrm{b}}$ & 6.6 & 170 & 65 & $1440(\mathrm{M})$ \\
\hline $2-8$ & 1.00 & 0.0155 & $0.05^{\mathrm{c}}$ & 6.6 & 170 & 65 & $1440(\mathrm{M})$ \\
\hline $2-9$ & 1.00 & 0.0155 & $0.01^{\mathrm{d}}$ & 6.6 & 170 & 65 & $1440(\mathrm{M})$ \\
\hline
\end{tabular}

The high resolution transmission electron microscopy (HRTEM) images were recorded on a JEOL JEM-2010 operating at an accelerating voltage of $200 \mathrm{kV}$ to observe the inner pore structures of sample. Small-angle X-ray powder diffraction (XRD) data were taken on an $X^{\prime}$ Pert MPD pro diffractometer (PANalytical, the Netherlands) using Ni-filtered $\mathrm{Cu} \mathrm{K \alpha}$ radiation $(\lambda=1.5418 \AA$ ). The data was collected from $0.5^{\circ}$ to $5^{\circ}(2 \theta)$, with a step size of $0.02^{\circ}$. $\mathrm{N}_{2}$ adsorption-desorption isotherms were measured with a QUANTACHROM analyzer (Autosorb-1, USA) at $77 \mathrm{~K}$ under continuous adsorption conditions. Prior to measurement, the materials were outgassed at $300{ }^{\circ} \mathrm{C}$ for $4 \mathrm{~h}$. The pore size distributions were analyzed with the supplied BJH software package form the adsorption branches of the isotherms.

\section{RESULTS AND DISCUSSION}

The molar ratio of TEOS/P123 has direct effect on the morphology and physical and chemical capability of the synthesized samples [4]. The HRTEM image of the typical samples displays a well-ordered 2Dmesostructure. The HRTEM image of the two samples synthesized by different mixed method is shown in Fig. 1. The HRTEM image confirms that two typical samples display a wellordered 2Dmesostructure. Cylindrical pores are arranged in the ordered hexagonal array. Morphology and physical and chemical property parameters of the samples are listed in Table 2.

Fig. 2 shows the small-angle XRD patterns of the samples in Table 2 with ultrasonic irradiation.

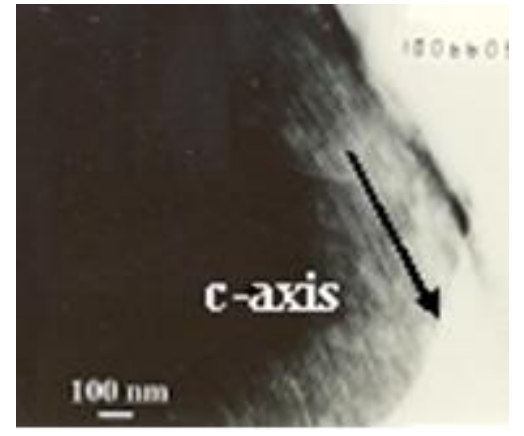

a

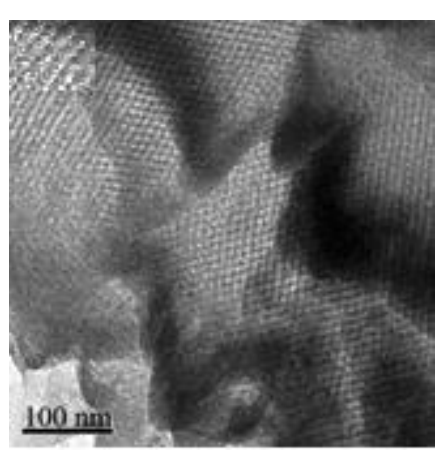

b

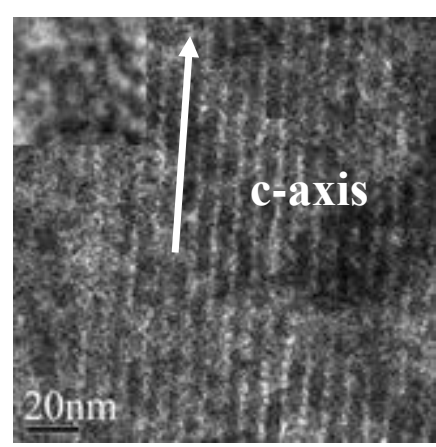

c

Fig. 1. TEM images of SBA-15: a-sample 1-2; b and c sample 1-6 
Except sample 1, all samples show three diffraction peaks, associated with the p $6 \mathrm{~mm}$ hexagonal symmetry, which is consistent with SBA-15 materials [1-6]. Sample 1-1 synthesized shows one peak, one calcined has no peak. This shows that the concentration of the surfactant is too small to cause the channel easily collapsed. For sample 1$2,1-3,1-4$, the values of $d$ spacing between the (100) planes of pores increased with the decrease of the molar ratios of TEOS/P123. Also, the size of particles increased. Morphology of the sample was changed from spherical to gyroidal shape. The small-angle XRD patterns of the samples in Table 2 with magnetic stirring are displayed in Fig. 2 and Fig. 3. The change regulation of morphology and physical and chemical capability of two kinds of samples was almost similar. For samples 1-5, 1-6, 1-7, the values of $d$ spacing between the (100) planes of pores increase with the increase in surfactant concentration. As surfactant concentration increased, the shape and size of the micelles greatly changed, resulting in their morphology and physical and chemical characteristics.

Although the nitrogen adsorption-desorption properties and BJH pore size distributions of MCM have been well reported in the previous literature [1]. Such performance of MCM synthesized with different Si/P123 molar ratios has not been reported before. We used ultrasonic irradiation as the control factors.

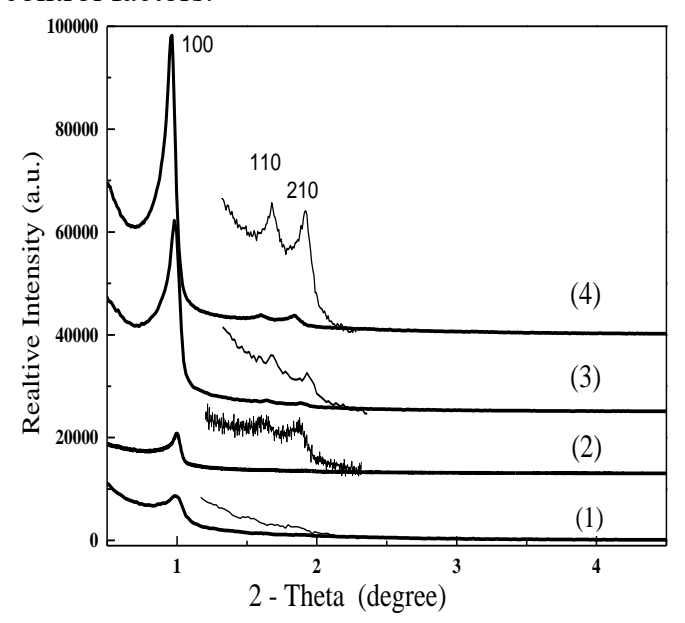

a

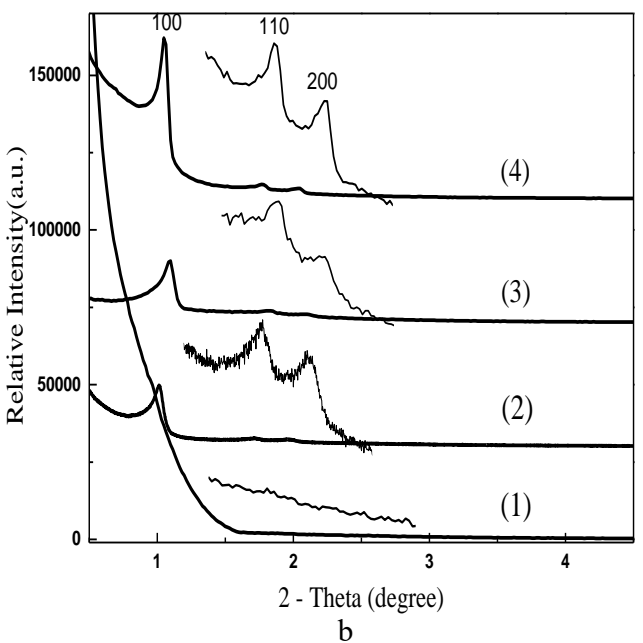

Fig 2. Low-angle XRD patterns: a-as-synthesized; $b$-calcined materials at (1) sample 1-1, (2) sample 1-2, (3) sample $1-3,(4)$ sample $1-4$
The nitrogen adsorption-desorption isotherms of the materials synthesized by ultrasonic irradiation are shown in Fig. 4, and the parameters are summarized in Table 3.

According to the international union of pure and applied chemistry (IUPAC), all of $\mathrm{N}_{2}$ isotherms for materials synthesized with $\mathrm{Si} / \mathrm{P} 123$ molar ratios in 58-116 basically can be defined as type IV. This result confirmed that cylindrical pores are open at both ends.
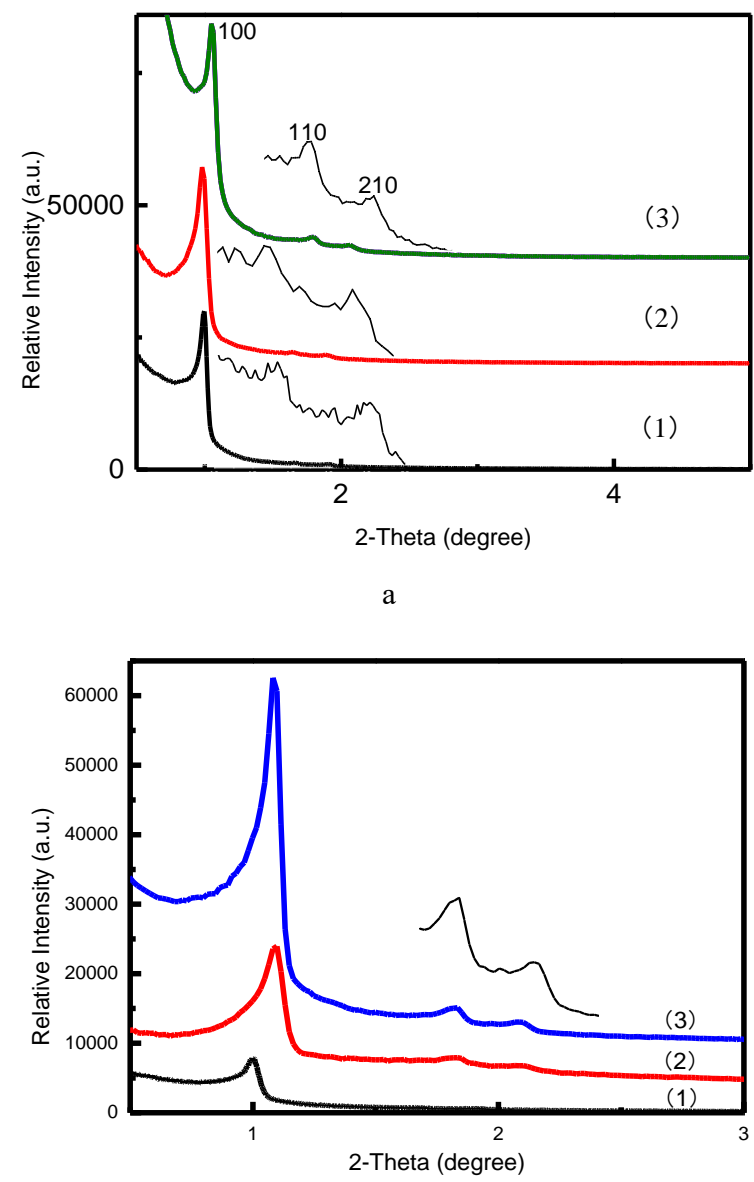

$\mathrm{b}$

Fig. 3. Low-angle XRD patterns: $a$-as-synthesized; $b$-calcined materials for (1) sample 1-5, (2) sample 1-6, (3) sample $1-7$

The Barret-Joyner-Halenda method (BJH) [3] was applied to calculate the pore size distribution. With Si/P123 molar ratio increasing, the $\mathrm{BJH}$ pore size of the materials shows a decrease from $8.24 \mathrm{~nm}$ to $6.13 \mathrm{~nm}$. Sample1-3 and sample 1-4 have narrower pore size distribution (Fig. 4), but sample 1-2 has relatively broader pore size distribution. This is in accordance with the results of SXRD. At $\mathrm{Si} / \mathrm{P} 123=116$, the ordering of the mesostructure decreases, as well as BJH pore size distributions are broader. Surprisingly, its BET surface area increases, the morphology is uniform and defined sphere.

Table 1 summarizes molar compositions and synthesis process parameters of MCM.

Fig. 4 shows SEM micrographs of solids obtained with different ultrasonic irradiation duration and surfactant molar ratios. It can be seen that prolonged ultrasonic irradiation leads to particles with different size and diversified morphology. By increasing ultrasonic 
irradiation duration, sample 2-5 SEM shows petal-like shape and more serious adhesion.

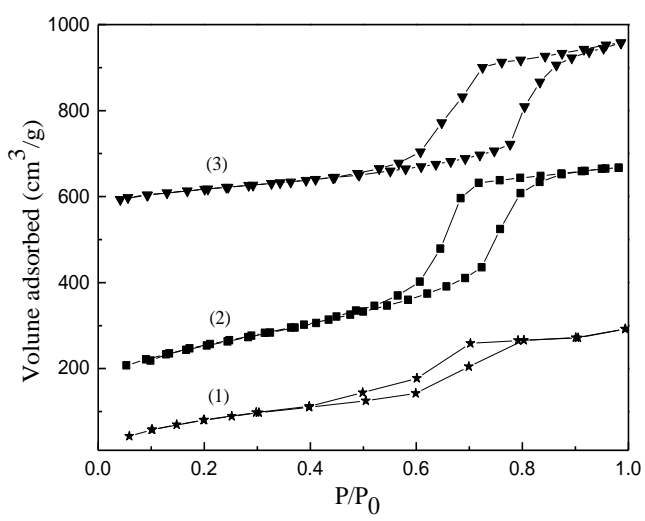

$\mathrm{a}$

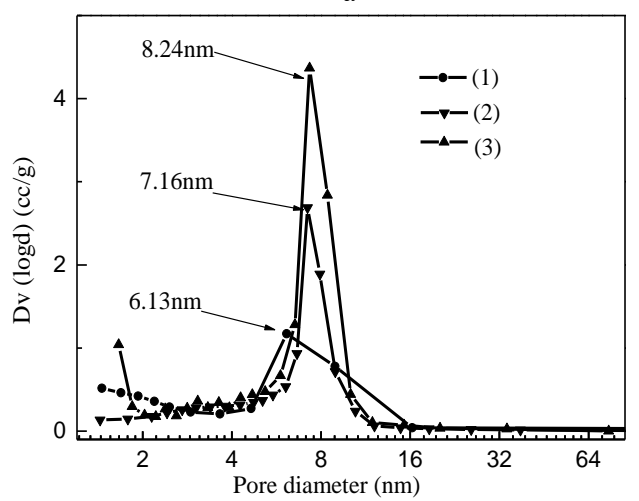

b

Fig. 4. $\mathrm{a}-\mathrm{N}_{2}$ adsorption-desorption isotherms; $b-\mathrm{BJH}$ pore size distribution of (1) sample 1-2, (2) sample 1-3, (3) sample $1-4$

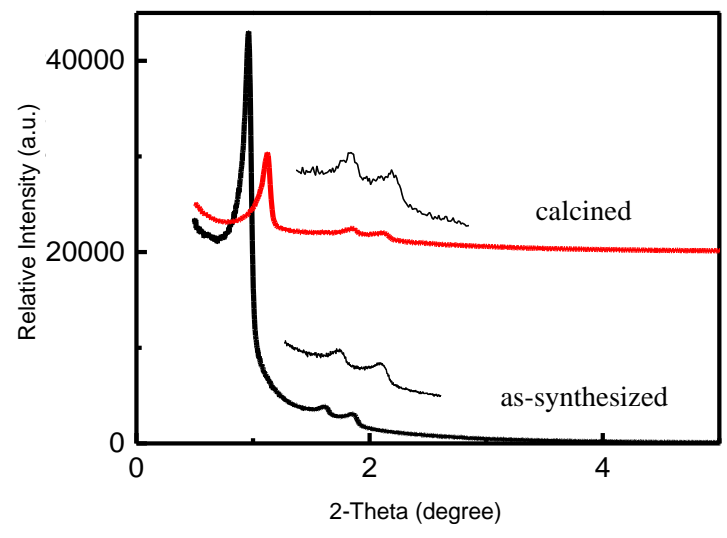

Fig. 5. 1-low-angle XRD patterns of as-synthesized; 21 calcined materials for sample 2-1

With increasing surfactant molar ratios, according to SEM, surfactant concentrations have large effect on morphology of particles.

The samples in Fig. 5 show three diffraction peaks, associated with the p6mm hexagonal symmetry, which was consistent with SBA-15 materials [1-6]. Highly energetic organic-inorganic interfaces favour to form six square flake-like particles whereas systems with high energy lead to the morphology with high energy. With decreasing to surfactant molar ratios and ultrasonic irradiation, system with lower energy leads to the morphology with lower energy, sphere-petal-like particles as shown in Fig. 4 sample 2-2SEM.

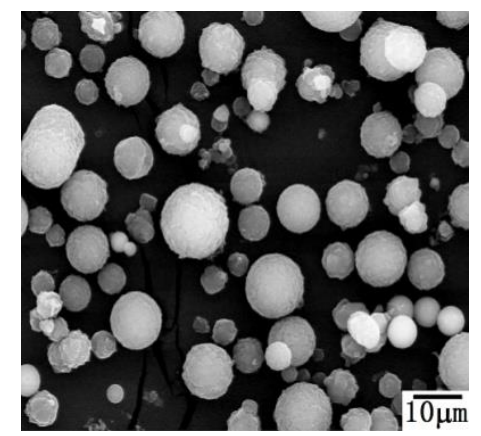

$\mathrm{a}$

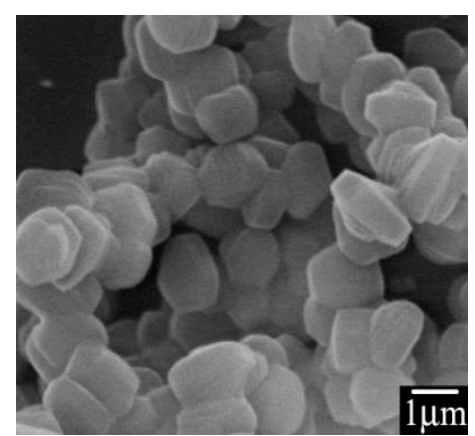

d

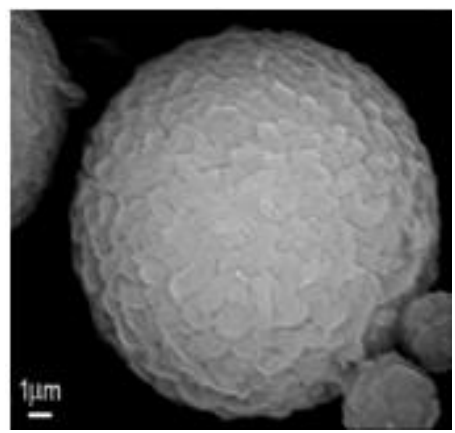

$\mathrm{b}$

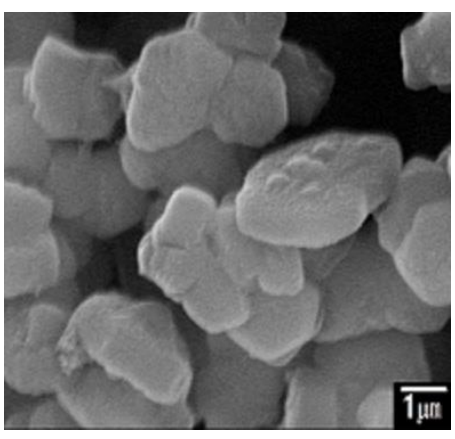

$\mathrm{e}$

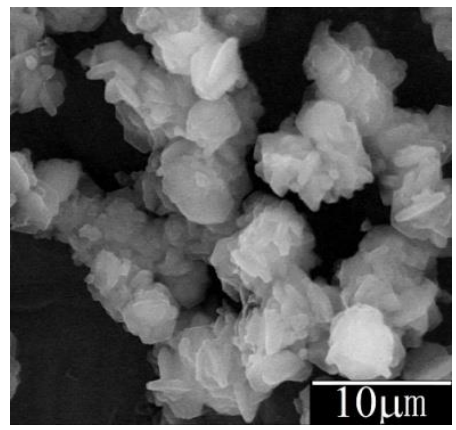

$\mathrm{c}$

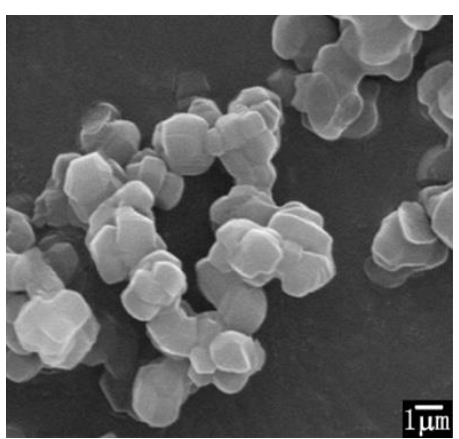

f

Fig. 6. SEM images of SBA-15 materials: a-sample 2-1 (magnification 1000 times); b-sample 2-1 (magnification 6000 times); c-sample 2-2; d-sample 2-3; e-sample 2-4; f-sample 2-5 
These particles were made up of smaller flake-like particles. With decreasing of ultrasonic irradiation duration at the same surfactant concentration, Sample 2-1 shows spheres that diameter is from a few microns to a few tens of microns with average diameter of about $5 \mu \mathrm{m}$. Sphere particles were made up of smaller particles. A serious of characterization results confirm that organic-inorganic interface function and interface energy plays an important role in morphology control.

In acidic media ( $\mathrm{pH}$ less than 2 ), where the siliceous species contain positive charges $\left(\mathrm{I}^{+}\right)$[30], and the surfactant was bound to $\mathrm{H}_{3} \mathrm{O}^{+}$to form positive charges $\mathrm{S}^{+}$ $\left[\mathrm{S}^{0}\left(\mathrm{H}_{3} \mathrm{O}^{+}\right)\right]$. The electrostatic charge interaction between the silica and the surfactant is mediated by $\mathrm{X}^{-}$anions to make up $\mathrm{S}^{+} \mathrm{X}^{-} \mathrm{I}^{+}$. $\mathrm{X}^{-}$is a transition metal acid radical. $\mathrm{M}^{+}$ instead of silicon species $\left(\mathrm{I}^{+}\right)$and surfactant $\left(\mathrm{S}^{+}\right)$embedded in the mesoporous framework formed transition-metal substituted mesoporous silicas. In mesoporous materials science, the embedding of transition metals does not match the morphology control. Fig. $9 \mathrm{c}$ and $\mathrm{d}$ show SEM morphology of mesoporous silicas synthesized by $\mathrm{Zr}^{4+}$ with irregular morphology. In Fig. 7 d, show sphere-like shapes that were made up of irregular shape particles. Fig. $7 \mathrm{~b}$ shows micrographs of mesoporous silica synthesized by
$\mathrm{Co}^{2+}$ whereappear fiber-like or rod-like shapes. At the same time, inorganic salts additions results in the same morphology in Fig. 7 a. The kinds of metal cations and valence charge have not only a certain effect on the morphology of the mesoporous materials, but also on its composition. For sample 2-7 and 2-9, only several small and broad diffraction peaks are observed in the wide-angle XRD patterns. The diffraction peaks corresponding to $\mathrm{Co}_{3} \mathrm{O}_{4}$ and $\mathrm{ZrO}_{2}$ nano-crystallites are more evident. Although magnetic $\mathrm{Co}_{3} \mathrm{O}_{4}$ usually converts to pure $\mathrm{Co}_{2} \mathrm{O}_{3}$, the amorphous silicate skeleton apparently prevented from the phase transition, stabilizing the $\mathrm{Co}_{3} \mathrm{O}_{4}$ when heated to $550{ }^{\circ} \mathrm{C}$. The results show that $\mathrm{Co}_{3} \mathrm{O}_{4}$ and $\mathrm{ZrO}_{2}$ substituted mesoporous silica framework were formed. The morphology of transition-metal substituted mesoporous silica is important for industrial application.

Formation of various morphology materials can follow three stages. The first stage is the self-assembly at the molecular level that was documented by Stucky group [31]. The second stage is colloid action-like of these surfactant/silica aggregate composites to form a new liquid crystal-like phase, and finally separates form the solution phase.

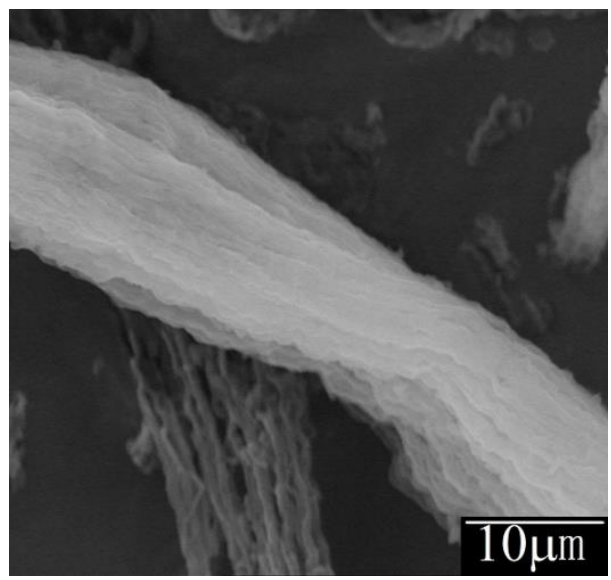

$\mathrm{b}$

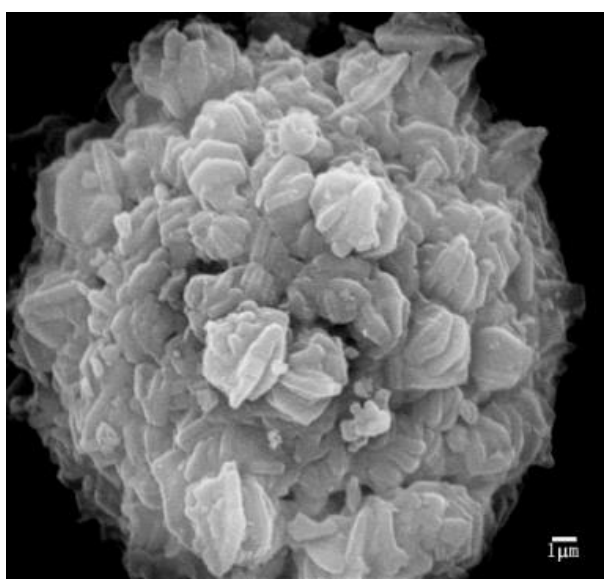

d

Fig. 7. SEM images of MCM sample 2-7, 2-8, 2-9 and 2-10 respectively for a, b, c and d 
We adopt two mixing methods in these stages, respectively ultrasonic irradiation and magnetic stirring. When a high intensity ultrasonic is applied in a liquid crystal, sonochemistry arises from acoustic cavitation, which consists of the formation, growth, and implosive collapse of bubbles. The collapse of bubbles generates localized hot spots with transient temperature as high as $\sim 5000 \mathrm{~K}$, pressures of $\sim 1800 \mathrm{~atm}$, and cooling rates in excess of $10^{10} \mathrm{~K} / \mathrm{s}$ [4]. It is known these extreme conditions attained can result in silica species different interconnection of the composite aggregates to form a new liquid crystal-like phase. SEM images of samples show more diversified morphology. Furthermore, inorganic salt and quiescent conditions are also crucial for morphological formation of samples. Materials prepared without static condition showed fiber-like morphology. Inorganic strong electrolytes can help to form more diversified morphology. Materials prepared with static condition showed very uniform and defined spheres morphology.

\section{CONCLUSIONS}

Diversified morphology of SBA-15 has been successfully synthesized by varying amount of surfactant at a relatively low concentration. Particles size in micronlevel is controllable through ultrasonic irradiation at first two stages. The morphological control with amount of surfactant, various inorganic salts and ultrasonic admixture method introduces more flexibility and diversity into the designed synthesis of diversified mesoporous composites materials. Such morphological mesoporous composites materials are promising for applications in molecule diffusion processes such as catalysis, separation, guest molecule encapsulation and internal surface modification.

\section{Acknowledgments}

This work was supported by the National Science Foundation of China for Youth (21307169).

\section{REFERENCES}

1. Kresge, C.T., Leonowicz, M.E., Roth, W.J., Vartuli, J.C., Beck, J.S. Ordered Mesoporous Molecular Sieves Synthesized by a Liquid-Crystal Template Mechanism Nature 359 1992: pp. 710-712.

2. Ying, J.Y., Mehnert, C.P., Wong, M.S. Synthesis and Application of Supramolecular-Templated Mesoporous Materials Angewandte Chemie International Edition 38 1999: pp. $56-77$

https://doi.org/10.1002/(SICI)1521

3773(19990115)38:1/2<56::AID-ANIE56>3.0.CO;2-E

3. Newalkar, B.L., Choudary, N.V., Turaga, U.T. Kumar, V.P., Komarneni, S., Bhat, T.S.G. Potential Adsorbent for Light Hydrocarbon Separation: Role of SBA15 Framework Porosity Chemistry of Materials 15 2003: pp. $1474-1479$.

https://doi.org/10.1021/cm020889d

4. Xie, H.L., Yu, R.B., Wang, D., Yao, J.X., Xing, X.R., Xu, W.G. Size and Morphology Control in Thesynthesis of SBA-15 Studies in Surface Science and Catalysis 165 2007: pp. $603-606$.

https://doi.org/10.1016/S0167-2991(07)80394-6
5. Carrero, A., Moreno, J., Aguado, J., Calleja, G. Control of SBA-15 Materials Morphology by Modification of Synthesis Conditions Studies in Surface Science and Catalysis 174 2008: pp. 321-324.

6. Wallis, P., Wohlrab, S., Kalevaru, V.N., Frank, M., Martin, A. Impact of Support Pore Structure and Morphology on Catalyst Performance of Vox/SPA-15 for Selective Methane Oxidation, Catalysis Today, available online 24 March 2016.

7. Qin, Y., Wang, Y., Wang, H.Q., Gao, J.S., Qu, Z.P. Effect of Morphology and Pore Structure of SBA-15 on Toluene Dynamic Adsorption/Desorption Performance Procedia Environmental Sciences 18 2013: pp. 366-371. https://doi.org/10.1016/j.proenv.2013.04.048

8. Crisci, A.J., Ticker, M.H., $\quad$ Lee, M.Y., Jang, S.G., Dumesic, J.A., Scott, S.L. Acid-functionalized SBA-15Type Silica Catalysts for Carbohydrate Dehydration $A C S$ Catalysis 1(7) 2011: pp. 719-728.

9. Johansson, E.M., Ballem, M.A., Córdoba, J.M., Odén, M. Rapid Synthesis of SBA-15 Rods with Variable Lengths, Widths, and Tunable Large Pores Langmuir 27 (8) 2011: pp. 4994-4999.

10. Kjellman, T., Reichhardt, N., Sakeye, M., Smatt, J.H., Lindén, M., Alfredsson, V. Independent Fine Tuning of the Intrawall Porosity and Primary Mesoporosity of SBA-15 Chemistry of Materials 25 (9) 2013: pp. 1989-1997. https://doi.org/10.1021/cm4009442

11. Cucinotta, F., Carniato, F., Paul, G., Bracco, S., Bisio, C., Caldarelli, S., Marchese, L. Incorporation of a Semiconductive Polymer into Mesoporous SBA-15 Platelets: Toward New Luminescent Hybrid Materials Chemistry of Materials 23 (11) 2011: pp. 2803-2809. https://doi.org/10.1021/cm103670w

12. Kubo, S., Kosuge, K. Salt-induced Formation of Uniform Fiberlike SBA-15 Mesoporous Silica Particles and Application to Toluene Adsorption Langmuir 23 (23) 2007: pp. $11761-11768$.

13. Xu, Q.Q., Xu, G., Yin, J.Z., Wang, A.Q., Ma, Y.L., Gao, J.J. Preparation of Superhighly Dispersed $\mathrm{Co}_{3} \mathrm{O}_{4} @$ SBA-15 with Different Morphologies in Supercritical $\mathrm{CO}_{2}$ with the Assistance of Dilute Acids Industrial and Engineering Chemistry Research 53 (25) 2014: pp. $10366-10371$.

14. Hukkamäki, J., Suvanto, S., Suvanto, M., Pakkanen, T.T. Influence of the Pore Structure Of MCM-41 and SBA-15 Silica Fibers on Atomic Layer Chemical Vapor Deposition of Cosba-15 Silica Fibers on Atomic Layer Chemica Vapor Deposition of Cobalt Carbonyl Langmuir 20 (23) 2004: pp. $10288-10295$.

15. Aktas, O., Yasyerli, S., Dogu, G., Dogu, T. Effect of Synthesis Conditions on the Structure and Catalytic Performance of V- and Ce-Incorporated SBA-15Like Materials in Propane Selective Oxidation Industrial and Engineering Chemistry Research 49 (15) 2010: pp. $6790-6802$. https://doi.org/10.1021/ie901672b

16. Menjoge, A.R., Huang, Q.L., Nohair, B., Eic, M., Shen, W., Che, R.C., $\quad$ Kaliaguine, S., Vasenkov, S. Combined Application of Tracer Zero Length Column Technique and Pulsed Field Gradient Nuclear Magnetic Resonance for Studies of Diffusion of Sorbate Molecule in Mesoporous Silica SBA-15 The Journal of Physical Chemistry 114 (39) 2010: pp. 16298-16308. https://doi.org/10.1021/jp105882s 
17. Kónya, Z., Zhe, J., Szegedi, A., Kiricsi, 1., Alivisatos, P., Somorjai, G.A. Synthesis and Characterization of Hyperbranched Mesoporous Silica SBA-15 Chemical Communications 2003: pp. 314-315. https://doi.org/10.1039/b210053c

18. Moulin, R., Schmitt, J., Lecchi, A., Deqrouard, J., Impérorclerc, M. Morphologies of Mesoporous SBA-15 Particles Explained by the Competition Between Interfacial and Bending Energies Soft Matter 9 (46) 2013: pp. $11085-11092$.

19. Besançon, M., Michelin, L., Josien, L., Vidal, L., Assaker, K., Bonne, M., Lebeau, B., Blin, J.L. Influence of the Porous Texture of SBA-15 Mesoporous Silica on the Anatase Formation in $\mathrm{Tio}_{2}-\mathrm{Sio}_{2}$ Nanocomposites New Journal of Chemistry 40 (5) 2016: pp. 4386-4397. https://doi.org/10.1039/C5NJ02859K

20. Fulvio, P.F., Pikus, S., Jaroniec, M. Tailoring Properties of SBA-15 Materials by Controlling Conditions of Hydrothermal Synthesis Journal of Materials Chemistry 15 (47) 2005: pp. 5049-5053.

21. Verma, P., Kuwahara, Y., Mori, K., Yamashita, H. Synthesis and Characterization of a $\mathrm{Pd} / \mathrm{Ag}$ Bimetallic Nanocatalyst on SBA-15 Mesoporous Silica as a Plasmonic Catalyst Journal of Materials Chemistry A 3 (37) 2015: pp. 18889-18897.

22. Kosuge, K., Sato, T., Kikukawa, N., Takemori, M. Morphological Control of Rod- and Fiberlike SBA-15 Type Mesoporous Silica Using Water-Soluble Sodium Silicate Chemistry of Materials 16(5) 2004: pp. 899-905. https://doi.org/10.1021/cm030622u

23. Sayari, A., Han, B.H., Yang, Y. Simple Synthesis Route to Monodispersed A-15 Silica Rods Journal of the American Chemical Society 126 (44) 2004: pp. 14348-14349. https://doi.org/10.1021/ja0478734

24. Tang, L., Fang, Y., Pang, Y., Zeng, G.M., Wang, J.J., Zhou, Y.Y., Deng, Y.C., Yang, G., Cai, Y., Chen, J. Synergistic Adsorption and Reduction of Hexavalent
Chromium Using Highly Uniform Polyaniline-Magnetic Mesoporous Silica Composite Chemical Engineering Journal 254 2014: pp. 302-312. https://doi.org/10.1016/j.cej.2014.05.119

25. Chen, J.E., Lian, H.Y., Dutta, S., Alshehri, S.M., Yamauchi, Y., Nquyue, M.T., Yonezawa, T., Wu, K.C. Synthesis of Magnetic Mesoporous Titania Colloidal Crystals Through Evaporation Induced Self-Assembly in Emulsion Effective and Recyclable Photocatalysts Physical Chemistry Chemical Physics 17 (41) 2015: pp. $27653-27657$.

26. Sahoo, B., Sahu, S.K., Nayak, S., Dhara, D, Pramanik, P. Fabrication of Magnetic Mesoporous Manganese Ferrite Nanocomposites as Efficient Catalyst for Degradation of Dye Pollutants Catalysis Science and Technology 2 (7) 2012: pp. $1367-1374$.

27. Kato, N., Kato, N. High-yield Hydrothermal Synthesis of Mesoporous Silica Hollow Capsules Microporous and Mesoporous Materials 219 2016: pp. 230-239. https://doi.org/10.1016/j.micromeso.2015.08.015

28. Wang, C., Tao, S.Y., Meng, C.G. Facile Fabrication of Magnetic Mesoporous Silica via Multifunctional Surfactant Self-Assembly and Oxidation Journal of Materials Chemistry 22 2012: pp. 7179-7186.

29. Tao, S.Y., Zhu, Z.Y., Meng, C.G., Wang, C. Preparation and Morphology Control of Magnetic Mesoporous Silica aia Metalorganic Amphiphiles Self-Assembly Microporous and Mesoporous Materials 171 2013: pp. 94-102. https://doi.org/10.1016/j.micromeso.2012.12.011

30. Iler, R.K. The Chemistry of Silica, Wiley-Interscience, New York, 1979, p. 866.

31. Zhao, D.Y., Feng, J.L., Huo, Q.S., Melosh, N., Fredrickson, G.H., Chmelka, B.F., Stucky, G.D. Triblock Copolymer Syntheses of Mesoporous Silica with Periodic 50 To 300 Angstrom Pores Science 279 (23) 1998: pp. $548-552$. 